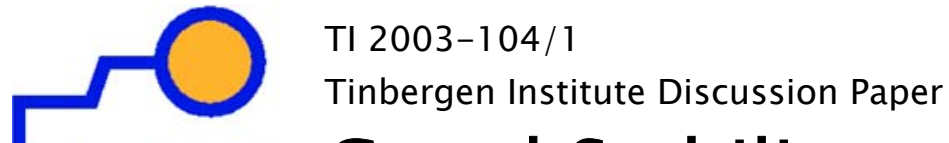 \\ Cartel Stability with Time-dependent Detection Probabilities
}

\author{
Jeroen Hinloopen
}

Faculty of Economics and Econometrics, Universiteit van Amsterdam, Tinbergen Institute, and Economics Network for Competition and Regulation (ENCORE). 


\section{Tinbergen Institute}

The Tinbergen Institute is the institute for economic research of the Erasmus Universiteit Rotterdam, Universiteit van Amsterdam, and Vrije Universiteit Amsterdam.

Tinbergen Institute Amsterdam

Roetersstraat 31

1018 WB Amsterdam

The Netherlands

Tel.: $\quad+31(0) 205513500$

Fax: $\quad+31(0) 205513555$

Tinbergen Institute Rotterdam

Burg. Oudlaan 50

3062 PA Rotterdam

The Netherlands

Tel.: $\quad+31(0) 104088900$

Fax: $\quad+31(0) 104089031$

Please send questions and/or remarks of nonscientific nature to driessen@tinbergen.nl.

Most TI discussion papers can be downloaded at http://www.tinbergen.nl. 


\title{
Cartel stability with time-dependent detection probabilities.
}

\author{
Jeroen Hinloopen, ${ }^{* \dagger}$ \\ University of Amsterdam (and Tinbergen Institute) \\ and \\ Economics Network for Competition and Regulation (ENCORE)
}

November 2003

\begin{abstract}
To account for the illegal nature of price-fixing agreements, detection probabilities are introduced in a dynamic oligopoly. For a trigger strategy to sustain a non-cooperative collusive equilibrium as a SPNE both the discount rate and all per-period detection probabilities must be 'low'. The domain reduces for which the strictest IC constraint is binding if (i) any per-period detection probability increases, (ii) prospective fine payments are increased, (iii) the period of limitation is reduced for violating antitrust laws.
\end{abstract}

Key words: Cartel stability, trigger strategy, detection probabilities, period of limitation.

JEL Classification: L12, L41

\footnotetext{
${ }^{*}$ Correspondence: University of Amsterdam, Faculty of Economics and Econometrics, Department of Economics, Roetersstraat 11, 1018 WB Amsterdam, The Netherlands; email: J.Hinloopen@uva.nl; http://www.fee.uva.nl/io/jhinloopen.

$\dagger$ This is a revised version of "Cartel stability with subjective detection beliefs", Tinbergen Institute Discussion Paper 03-008/2. For helpful comments and stimulating discussions thanks are due to Roy Epstein, Joe Harrington, Stephen Martin, Frank Verboven and seminar participants at the Dutch Antitrust Authority lunch seminar (November 2002), at the conference on "Competition and Market Power" as organized by the Research School SOM at Rijksuniversiteit Groningen (December 2002), the Katholieke Universiteit Leuven (February 2003), and at the annual conferences of the EUNIP in Turku (December 2002), of the IOS in Boston (April 2003), and of the EARIE in Helsinki (August 2003). Responsibility for the contents of the paper is solely mine.
} 


\section{Introduction}

Ever since the writings of Adam Smith economists are aware of firms' desire for coordinating their actions towards higher profits, coordination that typically is at the expense of consumer welfare. In his often-quoted intuition as to these coordinated actions Smith talks of "conspire", ${ }^{1}$ which captures nicely the fact that these coordinated actions are illegal although at the time of Smith's writing there was no such thing as antitrust law.

With the introduction of his "trigger strategy", Friedman (1971) provided a natural characterization of coordinated equilibria as subgame perfect noncooperative Nash equilibria thereby formalizing the celebrated Folk theorem. Applications of Friedman-type trigger strategies to describe cartel formations in oligopolies abound, including the analysis of price collusion and the concomitant choice of location (Friedman and Thisse, 1993), collusion by multi-market oligopolists in one market to dampen pro-competitive regulation in another market (Phillips and Mason, 1996), collusion under different degrees of product differentiation (Ross, 1992), collusion in sealed bid second price auctions (von Ungern-Sternberg, 1988), and collusion when competition is local (Verboven, 1998). ${ }^{2}$

The literature on non-cooperative collusion in oligopolies is just starting to address properly the fact that forming a price-fixing cartel is illegal, despite the wording of Smith and the promise of George Stigler. ${ }^{3}$ This is in part

${ }^{1}$ Smith $(1776,1986$, p. 232):

People of the same trade seldom meet together, even for meritment and diversion, but the conversation ends in a long conspiracy against the public, or in some contrivance to raise prices...

${ }^{2}$ An often-stated criticism is that Friedman's trigger strategy implies a too harsh punishment scheme for it to be realistic. In response to this critique a number of trigger strategies is developed with more intense but shorter lived punishment regimes, such as the "stick-and-carrot strategy" of Abreu (1986) and the "repentance strategy" of Segerstrom (1988). These strategies are applied much less however, in part because of their assumed hyperrational behaviour of individual agents. Also, experimental research shows that subjects involved in repeated prisoner's-dilemma-type stage games respond to defection with non-cooperative Nash behaviour for ever after (Mason and Phillips, 2002).

${ }^{3}$ Stigler (1964, p.45, emphasis added):

In deference to American antitrust policy, we shall assume that the collusion takes the form of joint determination of outputs and prices by ostensibly independent firms, but we shall not take account of the effects of the legal prohibitions until later.

The scarce studies that do take the existence of an antitrust authority explicitly into account include Motta and Polo (2003), and Harrington (2003a, b). 
due to the practical difficulty of providing enough convincing legal proof that independent firms display non-cooperative collusive behaviour. As noted by Segerstrom (1988), if all members adhere to the collusion rule and there are no external shocks that could break the cartel, defection is never observed. Indeed, showing that a 'true' competitive market equilibrium would yield different prices is hard in a world of reasonably stable prices quoted by (possibly many) independent competitors, especially if price-fixing induced excessive entry whereby profit margins are marginalized. Moreover, in oligopolistic markets it is difficult to distinguish between non-cooperative collusive behaviour and independent behaviour that takes into account rivals' actions. ${ }^{4}$

Yet, antitrust authorities increasingly are aware of the potential for (price) coordination in oligopolies. For instance, in its draft notice on the appraisal of horizontal mergers the European Commission considers in great length the increased possibility of illegal coordination in oligopolies after a proposed merger takes place (European Commission, 2002). The probability that firms engaged in non-cooperative concerted practises are successfully prosecuted is thus more than notional. Indeed, based on a sample of horizontal 184 price fixing cartels known to have existed in the US in the period 1961 to 1988 , Bryant and Eckard (1991) estimate the upper bound on the probability of uncaught pricing cartels to be somewhere between $13 \%$ and $17 \%$.

In this paper we consider explicitly the detection probability of a noncooperative collusive agreement within the context of a dynamic oligopoly. For that a commonly known mechanism is introduced that yields for any period a probability that the cartel is discovered. This probability-generating mechanism possibly is influenced by market characteristics such as the number of firms joining the cartel, the level of transparency in the market where the cartel operates, and the nature and abundance of resources available to antitrust authorities. In addition, the number of periods that the collusive agreement is in place is allowed to have an effect such that per-period detection probabilities can vary over time.

This set-up obviously yields a generalization of the incentive compatibility constraints for engaging in noncooperative collusive behaviour to be prof-

\footnotetext{
${ }^{4}$ This is exemplified for instance by the controversial decision of the European Court of Justice in the woodpulp case. Initially the European Commission condemned the concerted practises of a group of producers of bleached sulphate woodpulp on the basis of quite compelling evidence of price fixing agreements. The European Court of Justice agreed with the Commission that prices could have been fixed but stated at the same time that the Commission had failed in providing enough legal evidence to support this claim. In the end the Court ruled that due to the industry being an oligopoly with rapid transmission of information independent producers that are not engaged in any collusive agreement would also set prices according to the observed parallel pricing patterns (for more details see $A$. Ahlström $O Y$ and others v. EC Commission (1988) 4 CMLR 901; (1993) 4 CMLR 407).
} 
itable. In particular, for the trigger strategy to sustain a non-cooperative collusive equilibrium as a subgame perfect Nash equilibrium both the discount rate and all per-period detection probabilities have to be 'low enough'.

Analyzing further the incentive compatibility constraints of the non-stationary supergame reveals that an increase in any per-period detection reduces the domain for which the strictest incentive compatibility constraint is not binding. Additional results are obtained when considering two extensions of the base model; introducing fine payments after discovery, and considering explicitly the period of limitation that comes with violating antitrust laws. Prospective fine payments and detection probabilities appear to be substitutable instruments as an increase in either reduces the domain for which the strictest incentive compatibility constraint is not binding. At the same time the two instruments are complementary in that an increase in prospective fine payments yields more effect the higher are per-period detection probabilities, while an increase in any per-period detection probability yields more effect the higher are prospective fine payments. A possibly paradoxical result is that the domain shrinks for which the strictest incentive compatibility constraint is binding the longer is the period of limitation for violating antitrust law. This is due to defection becoming less profitable the longer the threat is present of prosecution and concomitant fine payments after the defection period.

We proceeds as follows. In the next section the model is specified and expected cartel adherence payoffs are derived. These are confronted with expected defection payoffs in Section 3 thus yielding the incentive compatibility constraints for the non-stationary supergame. Two examples, constant detection probabilities and detection probabilities that increase over time, are briefly considered in Section 4, while Section 5 analyzes the incentive compatibility constraints for the two extensions of the model. Section 6 concludes.

\section{The model}

At some point in time, i.e. $t=1$, a group of at least two, symmetric firms has agreed on a proposal to quote a joint price. This agreement is a noncooperative collusive agreement in the sense that it hinges exclusively on each individual cartel member's assessment of expected payoffs that come with quoting the agreed upon price (compliance) and those that come with quoting any other possible price (deviation). 


\subsection{Detection probabilities}

As of the moment that the cartel is formed each individual cartel member knows the probability that the antitrust authorities discover it in any future period. ${ }^{5}$ For period $t$ this detection probability equals $p_{t} \in(0,1)$, for $t=1,2, \ldots$, which is drawn from some commonly known discrete probability density function, $f(x ; \boldsymbol{\theta}(t))$ for $x=\{$ detection, no detection $\}$. The parameter vector $\boldsymbol{\theta}(t)$ contains all information that could affect the distribution of the per-period detection probabilities, such as the number of firms that has joined the cartel, the nature and abundance of resources available to the antitrust authorities, and the level of transparency in the market where the cartel operates. ${ }^{6}$ Through $\boldsymbol{\theta}(t)$ the per-period detection probabilities are possibly also influenced by the number of periods the cartel exists. For instance, the necessary proof for effectively dismantling a cartel can become more convincing the longer a cartel exists; parallel price changes are typically considered as suspicious, the more so the longer is the period for which parallel pricing is observed. ${ }^{7}$

Given the per-period detection probabilities the probability that the cartel is discovered as of period $t$ through period $t+k$ is given by (see also Figure 1):

$$
P_{t}(k)=1-\prod_{j=0}^{k}\left(1-p_{t+j}\right) .
$$

Note that $P_{t}(0)=p_{t}$, and that $P_{t}(k)$ is increasing in $k$, with $\lim _{k \rightarrow \infty} P_{t}(k)=$ 1 ; looking ahead 'far enough' always yields detection to be a certain event provided that there is a strictly positive per-period detection probability during each period. Indeed, given that antitrust authorities typically have limited funds, in any period there is just some chance that the antitrust authorities start investigating some possibly illegal cartel. But the overall probability that a particular cartel is chosen increases the more often it is among the potential candidates for investigation, especially if this choice is not made randomly but on the basis of (ever increasing) information. ${ }^{8}$

\footnotetext{
${ }^{5}$ Throughout we assume that detection implies not only that the cartel is discovered, but also that the antitrust authorities were able to provide all necessary legal proof for it to be dismantled.

${ }^{6}$ Within a context of colluding firms gradually adjusting their price towards the target level, $\boldsymbol{\theta}(t)$ would also be affected by the size of consecutive price adjustments (see Harrington, 2003b).

${ }^{7}$ In Section 3.1 the special case of weakly increasing per-period detection probabilities is analyzed in detail.

${ }^{8}$ Yet, because future cash flows (and fine payments, see Section 4 below) are discounted,
} 
period

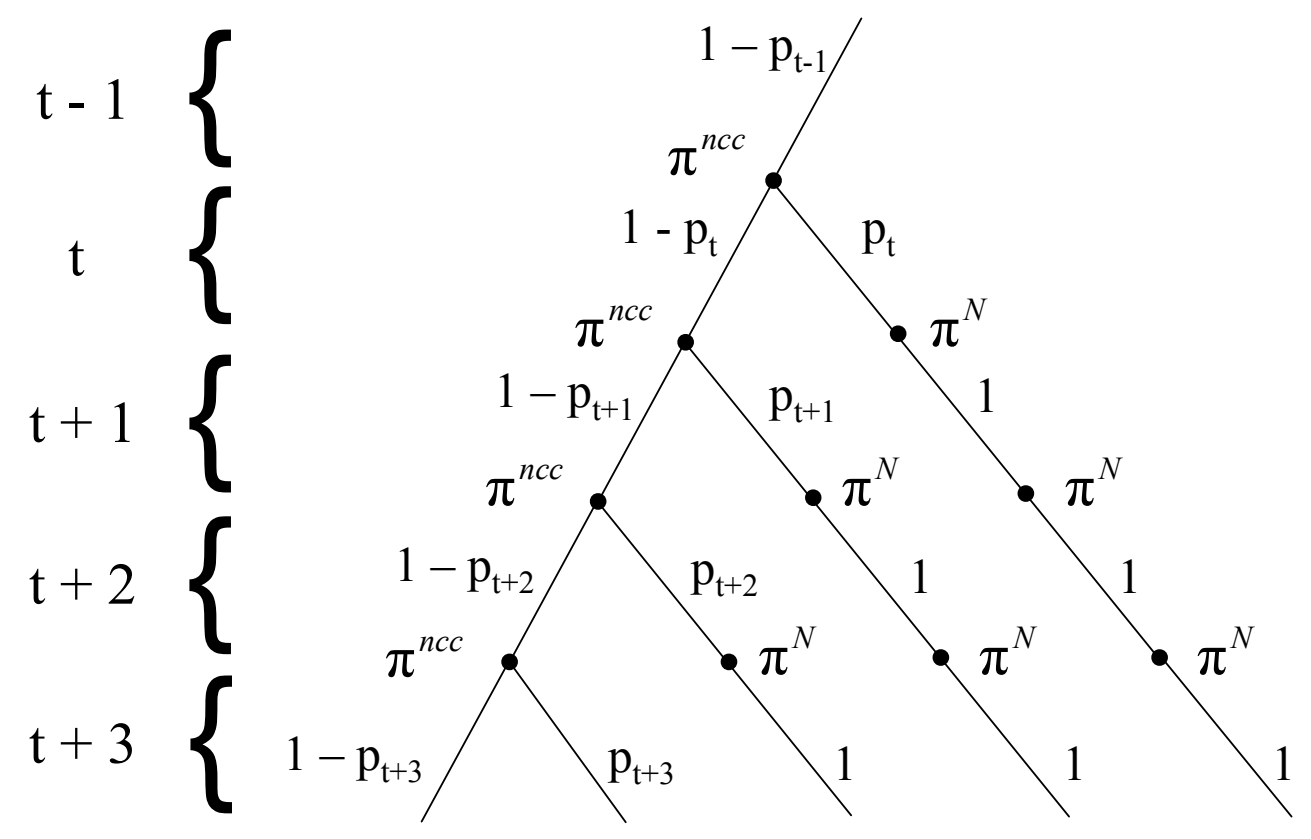

Figure 1: Development over time of expected cartel-adherence payoffs. 


\subsection{Compliance: strategy and expected payoff}

Let $p^{N}$ be the noncooperative Nash equilibrium price with an associated vector of quantities, $\left(q_{1}^{N}, \ldots q_{n}^{N}\right)$ such that $q_{i}^{N} \geq 0$, and $\sum_{i=1}^{n} q_{i}^{N}=D\left(p^{N}\right) .{ }^{9}$ This price can be anything as long as it is the result of individual profit-maximizing behaviour only. Likewise, let $p^{n c c} \in\left(p^{N}, p^{m}\right]$ be the noncooperative collusive price, where $p^{m}>p^{N}$ is the monopoly price. For supporting this coordinated equilibrium as a subgame perfect Nash equilibrium (SPNE) recall Friedman's (1971) trigger strategy profile:

$$
\begin{aligned}
s_{i}^{1} & =p^{n c c}, \\
s_{i}^{t} & =\left\{\begin{array}{l}
p^{n c c} \text { if } p_{j}^{k}=p^{n c c} \\
p^{N} \text { otherwise }
\end{array}, k=1, \ldots, t-1, j=1, \ldots, m,\right.
\end{aligned}
$$

$t=2, \ldots, i=1, \ldots, m$. The difference here with Friedman (1971) is that in addition to deviation, during each period the cartel can be discovered by the antitrust authorities. If this happens all cartel members realize noncooperative Nash equilibrium profits of the stage game only and the collusive agreement is dismantled for good. ${ }^{10}$ Hence, retaliation to the noncooperative Nash equilibrium occurs both after deviation and when the cartel is discovered. In the latter case it is, of course, not so much retaliation but an equilibrium forced upon the industry by the antitrust authorities.

Per-firm single-period noncooperative Nash equilibrium profits are denoted by $\pi^{N}=\left[D\left(p^{N}\right)-A C\left(q\left(p^{N}\right)\right)\right] q\left(p^{N}\right)$; per-firm single-period collusive profits are denoted by $\pi^{n c c}=\left[D\left(p^{n c c}\right)-A C\left(q\left(p^{n c c}\right)\right)\right] q\left(p^{n c c}\right)$. For engaging in coordinated actions to be profitable let $0 \leq \pi^{N}<\pi^{n c c}$. Cartel compliance profits earned during period $t+k$ as expected at the beginning of period $t$ then equal:

$$
v_{t}^{n c c}(k)=\left[1-P_{t}(k)\right] \pi^{n c c}+P_{t}(k) \pi^{N},
$$

where $\lim _{k \rightarrow \infty} v_{t}^{n c c}(k)=\pi^{N}$. Since $P_{t}(k)$ is increasing in $k$ it is immediate that the expected per-period value of cartel compliance is decreasing in $k$; the more distant is the future period considered, the lower is the expected per-period compliance profit (abstaining from any discounting).

our set-up does not imply that deviation is always preferred over compliance.

${ }^{9}$ In case all firms take the same action subscripts are ignored.

${ }^{10}$ Assuming that in the period during which the cartel is discovered firms earn noncooperative Nash profits rather than collusive profits is for computational convenience only; it does not affect any of the results reported below. 
If future periods are discounted with rate $\delta \in[0,1] \subset \mathbb{R}$, the expected present discounted value at the beginning of period $t$ of cartel compliance is given by:

$$
V_{t}^{n c c}=\sum_{i=0}^{\infty} \delta^{i} v_{t}^{n c c}(i) .
$$

\subsection{Deviation}

Whether or not the above defined trigger strategy can sustain the coordinated equilibrium as a SPNE depends on the alternative strategies that are open to individual firms. With probability $\left(1-p_{t+d}\right)$ firm $i$ earns defection profits $\pi_{i}^{\text {defect }}=\left[D\left(p_{i}^{\text {defect }}, p_{-i}^{n c c}\right)-A C\left(q\left(p_{i}^{\text {defect }}, p_{-i}^{n c c}\right)\right] q\left(p_{i}^{\text {defect }}, p_{-i}^{n c c}\right)\right.$ if it defects at the beginning of period $t+d$. To make defection credible let $\pi^{\text {defect }}>\pi^{n c c}>\pi^{N}$. During the same period the antitrust authorities can still find the defecting firm guilty of having participated in the illegal cartel, a finding that occurs with probability $p_{t+d} \cdot{ }^{11}$ If this happens the defecting firm (and all other cartel members) earns $\pi^{N} \cdot{ }^{12}$ Following Friedman (1971) assume that defection is always observed, also if in the same period the cartel is not discovered by the antitrust authorities. Accordingly, a detection period is always followed by reversion to non-cooperative Nash behaviour as of the next period for ever after.

Defection profits earned during period $t+d$ as expected at the beginning of period $t$ then equal:

$$
v_{t}^{\text {defect }}(d)=\left[1-P_{t}(d)\right] \pi^{\text {defect }}+P_{t}(d) \pi^{N},
$$

where $\lim _{d \rightarrow \infty} v_{t}^{\text {defect }}(d)=\pi^{N}$, and $\partial v_{t}^{\text {defect }}(d) / \partial d<0$; the more distant is the period during which defection is envisaged, the less likely it is that defection is still an option, the lower is the expected payoff for that period.

The expected present value at the beginning of period $t$ of defection during period $t+d$ then equals:

\footnotetext{
${ }^{11}$ In fact, retaliation typically involves relatively large reductions in price and could therefore attract the attention of the antitrust authorities. We ignore however the possible effect of defection on the probability that the cartel is discovered during the defection period (see Harrington (2003b) for an explicit treatment of this issue).

${ }^{12}$ Assuming that the defecting firm earns $\pi^{\text {defect }}$ with probability $\left(1-p_{t+d}\right)$ only is for computational convenience; assuming that the defecting firm earns $\pi^{\text {defect }}$ with certainty would not affect any of our conclusions stated below.
} 


$$
V_{t}^{\text {defect }}(d)=\sum_{i=0}^{d-1} \delta^{i} v_{t}^{n c c}(i)+\delta^{d} v_{t}^{\text {defect }}(d)+\sum_{i=d+1}^{\infty} \delta^{i} \pi^{N}
$$

\section{Cartel stability}

Comparing (4) with (6) yields the incentive compatibility constraints for (2) to sustain the coordinated equilibrium as a SPNE (see also Appendix 1):

$$
\frac{\pi^{\text {defect }}-\pi^{n c c}}{\pi^{n c c}-\pi^{C}} \leq \sum_{i=1}^{\infty} \delta^{i} \prod_{j=1}^{i}\left(1-p_{t+d+j}\right)=S(t+d),
$$

$t=1,2, \ldots, d=1,2, \ldots$. Obviously, $S(t+d)=S\left(t^{\prime}+d^{\prime}\right)$ for any $t^{\prime}$ and $d^{\prime}$ such that $t^{\prime}+d^{\prime}=t+d$. Accordingly, denote the RHS of (7) by $S(k)$, with $k=t+d$. Two relevant properties of $S(k)$ are that:

Lemma 1 If $\delta \in[0,1] \subset \mathbb{R}$ and $\exists t>1 \mid p_{t} \in(0,1) \subset \mathbb{R}$, then $\forall k>1$, (i) $S(k) \neq \emptyset$, and (ii) $S(k)$ is a monotone mapping from $\mathbb{N}_{+}$onto $\mathbb{R}_{+}$.

\section{Proof. See Appendix 2}

Lemma 1 implies that the minimum over $k$ of $S(k)$ exists and that it is unique. Hence, if the incentive compatibility constraint (7) is not binding for this minimum, the cartel will not break down due to the probability that it is discovered by the antitrust authorities. Likewise, the existence of an active antitrust authority as such does not necessarily preclude cartels being formed in the first place.

On the other hand, the folk theorem on infinitely repeated stage games being able to sustain any (coordinated) equilibrium as a SPNE provided that discount rates for future revenues are 'low enough', is qualified; the most binding incentive compatibility constraint could not be met even for low values of $\delta$ if at least one per-period detection probability is strictly positive and 'large enough'.

There are many occurrences thinkable that would alter the sequence of future per-period detection probabilities; changes in antitrust law providing the authorities with more effective tools, changes in market structure that affects the equilibrium number of firms, changes in rivals' behaviour, etc. The next proposition summarizes the effect of changes in any future perperiod detection probability on the incentive compatibility constraint for the minimum over $k$ of $S(k)$ : 
Proposition $2 \forall t>1$ an increase in $p_{t} \in(0,1) \subset \mathbb{R}$ reduces the domain for which the strictest incentive compatibility constraint is not binding.

Proof. Let $S\left(k^{*}\right)=\min _{\{k\}} S(k), k>1$. Then $\exists d^{*}>0 \mid 1+d^{*}=k^{*}$, and $\partial S\left(1+d^{*}\right) / \partial p_{t}<0 \forall t>1$.

Although cartel compliance could yield the highest expected discounted value when the non-cooperative collusive agreement is initiated, this could change in time when $f(x ; \boldsymbol{\theta}(t))$ changes. An increase in any (future) perperiod detection probability increases the likelihood that the strictest incentive compatibility constraint (7) will not be met. Existing cartels could then fall apart while potential cartels might not be formed at all. In the special case of detection being a certain event in some (future) period no cartel can exist nor will be formed.

It is important to note that this change in $f(x ; \boldsymbol{\theta}(t))$ is not to be attributed to time passing by (all future periods and all possible future deviation periods are taken into account in (7)), but to an exogenous change in $f$ and/or $\boldsymbol{\theta}(t)$. For instance, initially it might be that $f(x ; \boldsymbol{\theta}(t)) \sim U N I F(0,1)$, with $\boldsymbol{\theta}(t)=[0,1] \forall t>0$. Due to, say, increased funding the antitrust authorities are better able to track down illegal cartels. This could then have the effect that $\boldsymbol{\theta}(t)=[a, 1] \forall t>0$, with $a \in(0,1)$.

The empirical work of Ghosal and Gallo (2001) could be interpreted as supporting Proposition 2. They find that the number of cases considered by antitrust authorities is significantly affected by the extent of funding. A first explanation is, of course, that more funding means that more cases can be considered. A second explanation is that increased funding enhances the per-period detection probability for any cartel. According to Proposition 2 this would lead to the breakdown of an additional number of cartels, and all these shatters come with relative large price movements thence attracting the attention of the antitrust authorities.

\subsection{Special case 1: increasing per-period detection prob- abilities}

Yet, as alluded to above, an interesting special case is where per-period detection periods gradually increase over time. In particular, suppose $f(x ; \boldsymbol{\theta}(t))$ is such that $\forall i>j$ :

$$
p_{t+i}>p_{t+j}
$$

If $(8)$ holds we have that $\partial S(k) / \partial k<0$; the incentive compatibility constraint is most binding for the largest possible $t$ (and $d$ ), that is, for the 
limit of $\mathbf{p}=\left\{p_{1}, p_{2}, \ldots\right\}$. Denote $\sup \|\mathbf{p}\|=p^{*}<1$. The strictest incentive compatibility constraint (7) then becomes:

$$
\frac{\pi^{\text {defect }}-\pi^{n c c}}{\pi^{n c c}-\pi^{C}} \leq S\left(k^{*}\right)=\frac{\delta\left(1-p^{*}\right)}{1-\delta\left(1-p^{*}\right)} .
$$

The higher is the limit to which per-period detection probabilities converge, the stricter is the strictest incentive compatibility constraint. Yet, even if per-period detection probabilities are increasing in time but the limit is below 1 , breaking down of the cartel is not a certain event. ${ }^{13}$

\subsection{Special case 2: stationary super games}

Note that condition (7) requires for every future moment in time an assessment of compliance payoffs and deviation payoffs in any future period. For stationary supergames the number of assessments reduces significantly since for every period $t$ only one particular deviation period has to be considered.

Lemma 3 The supergame is stationary if, and only if, $p_{t}=p \in(0,1) \subset \mathbb{R}$ $\forall t$.

\section{Proof. See Appendix 3.}

According to Lemma 3 the game is stationary if detection probabilities are identical for each period. The stochastic part of the model then boils down to an infinite sequence of independent identical Bernoulli trials. Carteldiscovery probability (1) then simplifies to:

$$
P_{t}(k)=1-(1-p)^{k+1} .
$$

The strictest incentive compatibility constraint (7) is accordingly given by (9) with $p^{*}=p$. For the standard text book discount factor $\delta=(1+r)$, $r \in \mathbb{R}_{+}$, it reads as:

$$
\frac{\pi^{\text {defect }}-\pi^{n c c}}{\pi^{n c c}-\pi^{C}} \leq \frac{1-p}{r+p}
$$

\footnotetext{
${ }^{13}$ In the special case where all firms produce with the same technology summarized by constant marginal cost, where $\pi^{N}=0$, and where defection means setting a price $p_{i}^{\text {defect }}$ just below the collusive price such that the defecting firm captures the entire market, the incentive compatibility constraint $(9)$ reads as $\delta\left(1-p^{*}\right) \geq(m-1) / m$, where $m$ is the number if firms in the industry (see also Harrington, 1989).
} 


\section{Extensions}

In this section we consider two extensions of the basic model: including fine payments after discovery, and, in addition, including a finite period of limitation for violating antitrust laws.

\subsection{Fine payments}

In practise, if a cartel is broken up because antitrust authorities have discovered it, all former cartel members typically have to pay a fine $F \in(0, \bar{F}]$ once. The upper bound on fine payments is given by law and for an individual firm usually is defined as a percentage of gross annual per-firm revenue in the last year of the cartel's existence. ${ }^{14}$ Incorporating these penalties into the model yields at the beginning of period $t$ as expected fine payment in period $t+k$ (see also Figure 2):

$$
F_{t}(k)=\left\{\begin{array}{cc}
p_{t} F & \text { if } k=0, \\
{\left[1-P_{t}(k-1)\right] p_{t+k} F} & \text { otherwise. }
\end{array}\right.
$$

The relation between the expected per-period fine payment and perperiod detection probabilities is as follows:

$$
\left.\frac{\partial F_{t}(k)}{\partial p_{t+j}}\right|_{k>0}= \begin{cases}-\prod_{l=0, l \neq j}^{k-1}\left(1-p_{t+l}\right) p_{t+k} F<0, & j<k, \\ \prod_{l=0}^{k-1}\left(1-p_{t+l}\right) F>0, & j=k, \\ 0, & j>k .\end{cases}
$$

In case $k=0$ only the second and third part of (13) apply, having the same sign for the respective partial derivatives.

There is thus a one-to-one and positive relation between $F_{t}(k)$ and $p_{t+k}$; an increase in any per-period detection probability increases the expected fine for that period. At the same time, an increase in detection probability in period $t$ reduces the expected fine payment in any later period $t+j, j>0$, simply because the probability of reaching that future period as a cartel is reduced. In the long run the expected fine payment during any period is zero because the cartel is no longer expected to exist, that is, $\lim _{k \rightarrow \infty} F_{t}(k)=0$.

The net effect of these two opposite forces on the expected overall fine payment is positive; increasing any per-period detection probability raises the overall expected fine payment, as shown in the following lemma:

\footnotetext{
${ }^{14}$ See Article 15 of EU Council Regulation 17 for details of the EU practise; see Chapter 2 of the DoJ Antitrust Resource Manual (the "Sherman Act") for details of the US practise.
} 
period

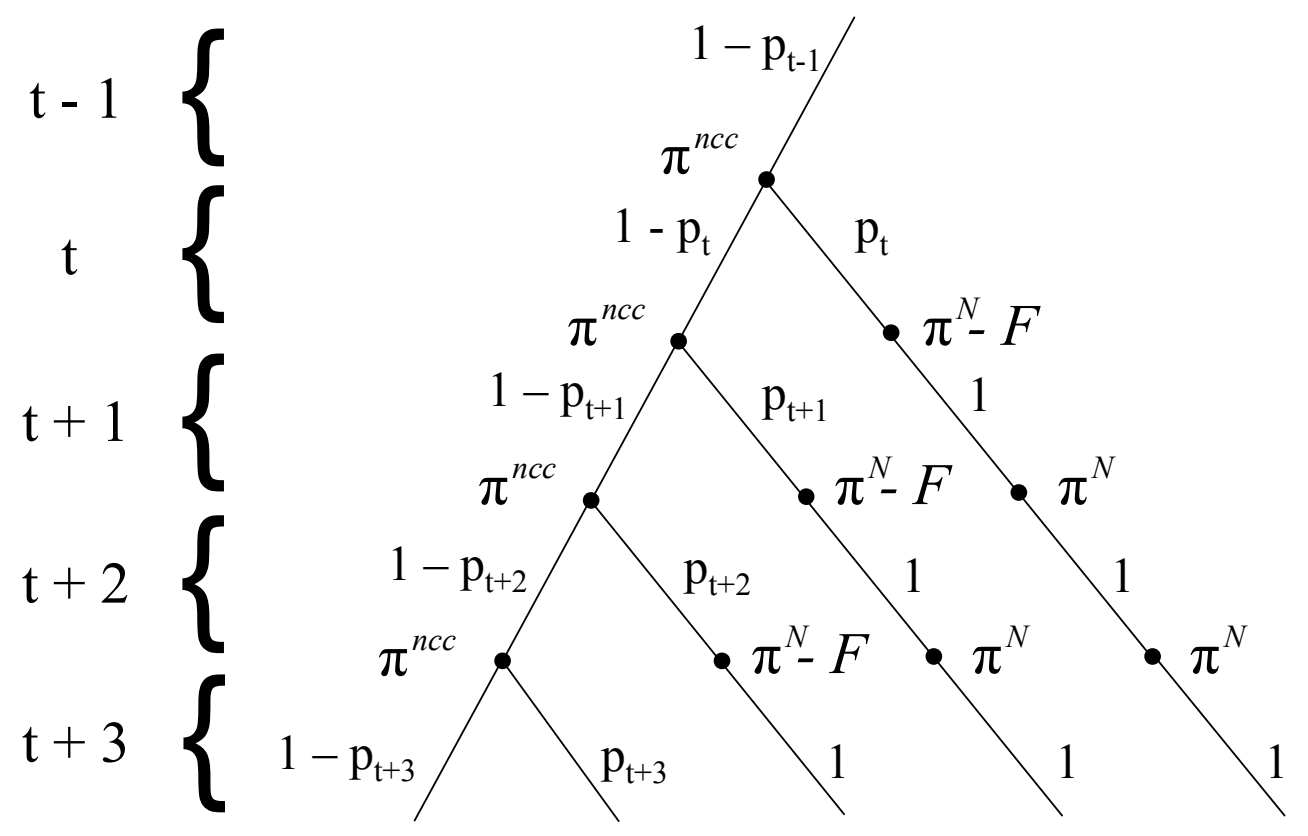

Figure 2: Development over time of expected cartel-adherence payoffs with fines. 
Lemma 4 If $\delta \in[0,1] \subset \mathbb{R}, p_{t} \in(0,1) \subset \mathbb{R}, F \in(0, \bar{F}) \subset \mathbb{R}_{+}, k \in \mathbb{N}$ then $\forall t>1$ and $j \in \mathbb{N}$ we have that $\partial \Gamma_{t}(k) / \partial p_{t+j}>0$, where $\Gamma_{t}(k)=\sum_{i=0}^{k} \delta^{i} F_{t}(i)$.

Proof. See Appendix 4

As before, defection during period $t$ is assumed not to affect the probability that the cartel is discovered in the same period. This means in particular that also during the defection period there is a possibility that the defecting firm has to pay the fine $F$. Comparing then $V_{t}^{\text {defect }}(d)-\Gamma_{t}(d)$ with $(3)$, realizing that the expected discounted value at the beginning of period $t$ of adherence during period $t+k$ equals $v_{t}^{n c c}(k)-F_{t}(k)$, yields as incentive compatibility constraints (see also Appendix 1):

$$
\frac{\pi^{\text {defect }}-\pi^{n c c}}{\pi^{n c c}-\pi^{N}} \leq S(t+d)-\widetilde{F} \sum_{i=1}^{\infty} \delta^{i} p_{t+d+i} \prod_{j=1}^{i-1}\left(1-p_{t+d+j}\right)=S_{F}(t+d)
$$

$t=1,2, \ldots, d=1,2, \ldots$, where $\widetilde{F}=F /\left(\pi^{n c c}-\pi^{N}\right)$. Note that a straightforward proof along the lines of that in Appendix 2 establishes that the minimum over $k$ of $S_{F}(k)$ exists and that it is unique, provided that $\bar{F}$ is such that $S_{F}(k)>0, \forall F \in(0, \bar{F}) \subset \mathbb{R}_{+}$.

Proposition 5 An increase in F reduces the domain for which the strictest incentive compatibility constraint is not binding.

Proof. Let $S_{F}\left(k^{*}\right)=\min _{\{k\}} S_{F}(k), k>1$. Then $\exists d^{*}>0 \mid 1+d^{*}=k^{*}$, and $\partial S_{F}\left(k^{*}\right) / \partial F=\partial S\left(k^{*}\right) / \partial F-\frac{1}{\left(\pi^{n c c}-\pi^{N}\right)} \sum_{i=1}^{\infty} \delta^{i} p_{1+d^{*}+i} \prod_{j=1}^{i-1}\left(1-p_{1+d^{*}+j}\right)<0$ $\forall p_{t} \mid p_{t} \in(0,1) \subset \mathbb{R}$.

For an individual firm increasing fine payments thus reduces the likelihood that a noncooperative collusive agreement is profitable in an expected sense. Larger fine payments reduce both the expected single-period defection profits and the expected single-period noncooperative collusive profits. As a result the incentive compatibility constraint becomes more strict since an increase in fine payments does not affect the expected per-period noncooperative Nash profits.

The strictest incentive compatibility constraint in (14) implicitly defines the penalty that erases every current and future cartel, being the fine that follows from $S_{F}\left(k^{*}\right) \leq 0$. As an example consider the stationary case with $p_{t}=p \forall t>0$, whereby $S_{F}(t+d)=\delta[1-p(1+\widetilde{F})] /[1-\delta(1-p)]$. The fine that makes the incentive compatibility constraint always binding follows from $\widetilde{F} \geq(1-p) / p$. Define $F=\gamma \pi^{n c c}$, where $\gamma \in(0,1) \subset \mathbb{R}$, and assume that 
$\pi^{N}=0$ (see also footnote 13). Accordingly, $\widetilde{F}=\gamma$. Then, for $\gamma=0.1$ (the legal maximum), the per-period detection probabilities have to be at least $1 / 1.1 \approx 0.91$ for prospective fine payments always to lead to the breakdown of every (potential) cartel.

In sum, both increasing prospective fine payments and increasing perperiod detection probabilities reduce the domain for which the strictest incentive compatibility constraint is not binding. Fine payments and detection probabilities are thus substitutable instruments for breaking down illegal cartels. At the same time the two instruments are complementary in that either supports the effectiveness of the other. From the proof of Proposition 5 it is immediate that $\left|\partial^{2} S_{F}\left(k^{*}\right) / \partial F \partial p_{t}\right|>0$; increasing any future perperiod detection probability reduces more the domain for which the strictest incentive compatibility constraint is not binding, the larger is the prospective fine payment. Likewise, it is straightforward to show that (see also the proof of Lemma 4) $\left|\partial^{2} S_{F}\left(k^{*}\right) / \partial p_{t} \partial F\right|>0$; increasing prospective fine payments reduces more the domain for which the strictest incentive compatibility constraint is not binding, the larger is any future per-period detection probability.

\subsection{Period of limitation}

Antitrust authorities typically have the legal right to continue to prosecute illegal cartels after their last period of existence; there is a particular period of limitation that comes with violating antitrust laws. Assuming this limitation period to extend over $n$ periods after the defection period yields for the present discounted value at the beginning of period $t$ of the expected fine payment when defecting at the beginning of period $t+d$ :

$$
\Gamma_{t}(d+n)=\sum_{i=0}^{n+d} \delta^{i} F_{t}(i) .
$$

Obviously, $\Gamma_{t}(d+n)$ is increasing in $n$; the longer is the period of limitation, the higher is the expected fine payment after defection.

Comparing then the expected present discounted value of defection during period $t+d, V_{t}^{\text {defect }}(d)-\Gamma_{t}(d+n)$, with the expected value of complying to the non-cooperative collusive agreement (3), again using $v_{t}^{n c c}(k)-F_{t}(k)$ as expected per-period compliance payoffs, yields as incentive compatibility constraints:

$$
\frac{\pi^{\text {defect }}-\pi^{n c c}}{\pi^{n c c}-\pi^{C}} \leq S_{F}(t+d)+\sum_{i=1}^{n} \delta^{i} \widetilde{F}_{t}(i+d)=S_{F, n}(t+d),
$$


$t=1,2, \ldots, d=1,2, \ldots$. The existence and uniqueness of the minimum over $k$ of $S_{F, n}(k)$ are again straightforward to establish along the lines of the proof in Appendix 2 (again under the provision that $\bar{F}$ is such that $S_{F, n}(k)>0, \forall$ $F \in(0, \bar{F}) \subset \mathbb{R}_{+}$.

Proposition 6 An increase in $n$ reduces the domain for which the incentive compatibility constraint is binding.

Proof. Let $S_{F, n}\left(k^{*}\right)=\min _{\{k\}} S_{F, n}(k), k>1$. Then $\exists d^{*}>0 \mid 1+d^{*}=k^{*}$, and $\forall p_{t} \mid p_{t} \in(0,1) \subset \mathbb{R}, n \geq 1$, and $F>0$ we have that $S_{F, n+1}\left(1+d^{*}\right)-$ $S_{F, n}\left(1+d^{*}\right)=\delta^{n} F_{1}\left(d^{*}+n\right)>0$.

According to Proposition 6 the strictest incentive compatibility constraint becomes 'less binding' the longer antitrust authorities continue to prosecute former cartel members after defection. Legislation that extends the period of limitation for violating antitrust laws strengthens rather than weakens cartel stability. This possibly paradoxical result is due to the reduction in expected defection profits as a result of an extended period of limitation; defection becomes less profitable the longer the threat is present of prosecution and concomitant fine payment after defection.

\section{Conclusions}

While studies of non-cooperative collusive behaviour abound, none of these has explicitly considered the possibility that antitrust authorities discover and put an end to this illegal activity. In this paper we have introduced per-period detection probabilities that can vary over time in a repeated prisoners' dilemma setting. A first result is that for a trigger strategy to sustain a non-cooperative collusive equilibrium as a SPNE both the discount rate and all per-period detection probabilities have to be 'low enough'. Analyzing further the incentive compatibility constraints of the concomitant nonstationary supergame reveals that an increase in any per-period detection probability reduces the domain for which the strictest of these constraints is not binding. The same happens when prospective fine payments are increased and/or when the period of limitation that comes with violating antitrust laws is reduced. The latter result is due to defection becoming more profitable the shorter the threat is present of prosecution and concomitant fine payments after defection. Prospective fine payments and per-period detection probabilities are shown to be substitutes in the sense that an increase in either reduces the domain for which the strictest incentive compatibility constraint is not binding. The two instruments are also shown to be complementary; 
the extent to which the domain is reduced for which the strictest incentive compatibility constraint is not binding due to an increase in prospective fine payments or per-period detection probabilities is enhanced the larger are, respectively, per-period detection probabilities and prospective fine payments.

As with any generalization of a widely used principle our analysis qualifies studies using that principle. Especially in the field of cartel formation in oligopolistic industries there is ample scope for applying the presently developed framework to specific applications of Friedman's trigger strategy that have ignored the possible detection of the cartel by the antitrust authorities.

\section{References}

[1] Abreu, D., 1986, "Extremal equilibria of oligopolistic supergames", Journal of Economic Theory, 39, No. 1, pp. 191 - 225.

[2] Bryant, P. G. and Eckard, E. W., 1991, "Price fixing: the probability of getting caught", The Review of Economics and Statistics, 73, pp. 531 536.

[3] European Commission, 2002, "On the appraisal of horizontal mergers under the Council Regulation on the control of concentrations between undertakings", Draft Commission Notice, 2002/C 331/03.

[4] Friedman, J. W., 1971, "A non-cooperative equilibrium for supergames", Review of Economic Studies, 38, pp. 1 - 12.

[5] Friedman, J. W. and Thisse, J.-F., 1993, "Partial collusion fosters minimum product differentiation", RAND Journal of Economics, 24, No. 4, pp. $631-645$.

[6] Ghosal, V. and Gallo, J., 2001, "The cyclical behavior of the Department of Justice's antitrust enforcement activity", International Journal of Industrial Organization, 19, pp. $27-54$.

[7] Harrington, J. E., Jr., 1989, "Collusion among asymmetric firms", International Journal of Industrial Organization, 7, pp. 289 - 307.

[8] Harrington, J. E., Jr., 2003a, "Some implications of antitrust laws for cartel pricing", Economics Letters, 79, pp. 377 - 383.

[9] Harrington, J. E., Jr., 2003b, "Cartel pricing dynamics in the presence of an antitrust authority", manuscript, Johns Hopkins University, http://www.econ.jhu.edu/People/Harrington/wp487_harrington.pdf. 
[10] Mason, C. F. and Phllips, O. R., 2002, "In support of trigger strategies: experimental evidence from two-person noncooperative games", Journal of Economics 83 Management Strategy, 11, No. 4., pp. 685 - 716.

[11] Mas-Colell, A., Whinston, M. D. and Green, J. F., 1995, Microeconomic Theory, Oxford: Oxford University Press.

[12] Motta, M. and Polo, M., 2003, "Leniency programs and cartel prosecution", International Journal of Industrial Organization, 21, Issue 3, pp. $347-380$.

[13] Phillips, O. R. and Mason, C. F., 1996, "Market regulation and multimarket rivalry", RAND Journal of Economics, 27, No. 3, pp. 596 617.

[14] Ross, T. W., 1992, "Cartel stability and product differentiation", International Journal of Industrial Organization, 10, No. 1, pp. 1 - 13.

[15] Smith, A., 1776, An inquiry into the nature and cause of the wealth of nations, use is made of reprinted version in the Penguin Classics series (1986), London: Penguin Books.

[16] Stigler, G. J., 1964, "A theory of oligopoly", Journal of Political Economy, 72, Issue 1, pp. $44-61$.

[17] Segerstrom, P. S., 1988, "Demons and repentance", Journal of Economic Theory, 45, No. 1, pp. $32-52$.

[18] Verboven, F., 1998, "Localized competition, multimarket operation, and collusive behaviour", International Economic Review, 39, No. 2, pp. 371 -398 .

[19] von Ungern-Sternberg, T., 1988, "Cartel stability in sealed bid second price auctions", Journal of Industrial Economics, 36, No. 3, pp. 351 358.

\section{Appendix 1 Incentive compatibility}

Comparing $V_{t}^{n c c}$ with $V_{t}^{\text {defect }}(d)$ first yields:

$$
\frac{\pi^{\text {defect }}-\pi^{n c c}}{\pi^{n c c}-\pi^{C}} \leq \frac{1}{1-P_{t}(d)} \sum_{i=1}^{\infty} \delta^{i}\left[1-P_{t}(d+i)\right] .
$$

Then note that $\left[1-P_{t}(d+i)\right] /\left[1-P_{t}(d)\right]=\prod_{j=1}^{i}\left(1-p_{t+d+j}\right)$. 


\section{Appendix 2 Proof of Lemma 1}

(i) Suppose $\exists k>0 \mid S(k)=\emptyset$, then $\sum_{i=1}^{\infty} \delta^{i} \prod_{j=1}^{i}\left(1-p_{k+j}\right)=\emptyset$, or $\prod_{j=1}^{i}\left(1-p_{k+j}\right)=$ $\emptyset \forall i>0$, given that $\delta \in[0,1] \subset \mathbb{R}$. Yet, if $p_{t} \in(0,1) \subset \mathbb{R} \forall t>0$ then $\prod_{j=1}^{i}\left(1-p_{j}\right) \neq \emptyset$, a contradiction.

(ii) Repeated substitution yields:

$$
S(k)=\sum_{i=1}^{l} \delta^{i} \prod_{j=1}^{i}\left(1-p_{k+j}\right)+\delta^{l} \prod_{j=1}^{l}\left(1-p_{k+j}\right) S(k+l),
$$

$l \in \mathbb{N}, k \in \mathbb{N}^{+}$. Setting $S(k)=S(k+l)$ yields:

$$
S(k+l)=\frac{\sum_{i=1}^{l} \delta^{i} \prod_{j=1}^{i}\left(1-p_{k+j}\right)}{1-\delta^{l} \prod_{j=1}^{l}\left(1-p_{k+j}\right)}=\sum_{i=1}^{\infty} \delta^{i} \prod_{j=1}^{i}\left(1-p_{k+j}\right)=S(k) .
$$

Equality (17) holds for $\lim _{p_{t} \rightarrow 0} \forall t>1$. Yet, $\left|\partial L H S_{(17)} / \partial p_{t}\right|>\left|\partial R H S_{(17)} / \partial p_{t}\right|$ $\forall t>1$, thus contradicting the claim that $S(k)=S(k+l)$ for $p_{t} \in(0,1) \subset \mathbb{R}$ $\forall t>0$.

\section{Appendix 3 Proof of Lemma 3}

Stationarity requires (see e.g. Mas-Colell, 1995, p. 734):

$$
V_{t}^{n c c} \geq V_{t}^{\text {defect }}(k) \Leftrightarrow V_{t}^{n c c} \geq V_{t}^{\text {defect }}\left(k^{\prime}\right), \forall k \neq k^{\prime} .
$$

For $k^{\prime}=0$, condition (7) is:

$$
\frac{\pi^{\text {defect }}-\pi^{n c c}}{\pi^{n c c}-\pi^{C}} \leq \frac{1}{1-p_{t}} \sum_{i=1}^{\infty} \delta^{i}\left[1-P_{t}(i)\right] .
$$

Stationarity thus holds if, and only if, $\forall k>0$ :

$$
\frac{1}{1-p_{t}} \sum_{i=1}^{\infty} \delta^{i}\left[1-P_{t}(i)\right]=\frac{1}{1-P_{t}(k)} \sum_{i=1}^{\infty} \delta^{i}\left[1-P_{t}(i+k)\right]
$$

or: 


$$
\sum_{i=1}^{\infty} \delta^{i} \prod_{j=1}^{i}\left(1-p_{t+j}\right)=\sum_{i=1}^{\infty} \delta^{i} \prod_{j=k+1}^{i+k}\left(1-p_{t+j}\right) .
$$

That is, $\forall i, k>0$ it must be that:

$$
\prod_{j=1}^{i}\left(1-p_{t+j}\right)=\prod_{j=k+1}^{i+k}\left(1-p_{t+j}\right) .
$$

For $i=1$ we have that $\left(1-p_{t+1}\right)=\left(1-p_{t+k}\right)$, which holds $\forall k>1$ if, and only if $p_{t}=p, \forall t$.

\section{Appendix 4 Proof of Lemma 4}

First note that $\Gamma_{t}(k)$ is the overall expected fine payment at the beginning of period $t$ through period $t+k$. Then:

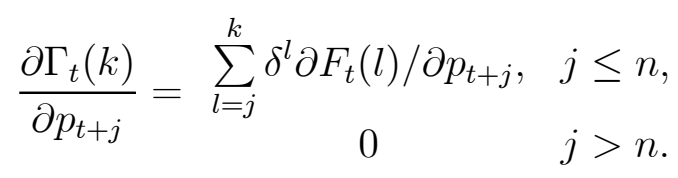

Since firms consider all future periods, restrict attention to $j \leq k$. Using (13) we have:

$$
\sum_{l=j}^{k} \delta^{l} \frac{\partial F_{t}(l)}{\partial p_{t+j}}=\delta^{l} \prod_{l=0}^{j-1}\left(1-p_{t+l}\right) F-\delta^{l+1} \prod_{l=0, l \neq j}^{j}\left(1-p_{t+l}\right) p_{t+j+1} F-\ldots-\delta^{k} \prod_{l=0, l \neq j}^{k-1}\left(1-p_{t+l}\right) p_{t+k} F
$$

For (18) to be positive it is sufficient to show that it is positive for $\delta=1$. In that case (18) translates into:

$$
\sum_{l=j}^{k} \delta^{l} \frac{\partial F_{t}(l)}{\partial p_{t+j}}=\prod_{l=0, l \neq j}^{k}\left(1-p_{t+l}\right)>0
$$

